\title{
Compreensão da Sexualidade por Jovens com Diagnóstico de Deficiência Intelectual
}

\author{
Aida Souza Morales ${ }^{2}$ \\ Cecília Guarnieri Batista \\ Universidade Estadual de Campinas
}

\begin{abstract}
RESUMO - O estudo descreve a compreensão de conceitos sobre sexualidade por jovens com diagnóstico de deficiência intelectual, em aulas de orientação sexual. A análise de episódios selecionados a partir das transcrições das videogravações de cinco aulas (Corpo Humano, Beijo, Namoro, Coito e Camisinha/DST) permitiu evidenciar: apropriação e compreensão de conceitos, dificuldades parciais de compreensão e inibição. A análise das transcrições indicou que todos os alunos se mostraram atentos, executaram as tarefas propostas e responderam em conjunto às perguntas. Observou-se que os sinais de embaraço e valores expressados eram semelhantes aos dos jovens em geral, indicando apropriação de valores culturalmente estabelecidos. As evidências obtidas contrastam com as visões míticas em relação à sexualidade desses jovens e sugerem mais estudos sobre suas competências.
\end{abstract}

Palavras-chave: formação de conceitos; educação sexual; sexualidade; deficiência intelectual.

\section{Understanding Sexuality by Youngsters with Diagnostic of Intellectual Deficiency}

\begin{abstract}
The study describes the comprehension of concepts about sexuality by youths diagnosed with intellectual deficiency, during classes on sexual education. The analysis of selected episodes from video transcriptions of five classes (Human Body, Kiss, Flirting, Coitus, Condom/STD) showed: the appropriation and understanding of concepts, partial difficulties of comprehension, and inhibition. The analysis of the transcripts indicated that all students were attentive to the classes, participated in the proposed tasks, and answered the questions. The observed signs of inhibition and the expression of values were similar to those observed in other youngsters, indicating the appropriation of culturally established values. The obtained evidences contrast with mythical visions related to sexuality in these youngsters, and suggest more studies about their competences.
\end{abstract}

Keywords: concept formation, sexual education, sexuality and intellectual deficiency.

O conceito de deficiência intelectual preconizado pela AAIDD (American Association on Intellectual and Developmental Disabilities) ${ }^{3}$, e descrito por Luckasson e cols. (2006), caracteriza-se por "limitações significativas, tanto no funcionamento intelectual quanto no comportamento adaptativo, como também nas habilidades adaptativas conceituais, sociais e práticas. Esta deficiência origina-se antes dos 18 anos" (p. 209). Os autores esclarecem que, para o diagnóstico, deve-se considerar o contexto social e as características das pessoas da mesma faixa etária e da mesma cultura do avaliado, as diferenças culturais e linguísticas, bem como a comunicação, os fatores sensoriais, motores e comportamentais. Enfatizam também que, na avaliação, é

1 O trabalho é fruto da pesquisa de mestrado de Aida Souza Morales, concluído em fevereiro/2008 junto ao Programa de Pós-graduação Saúde da Criança e do Adolescente, FCM-Unicamp, sob a orientação de Cecília Guarnieri Batista.

2 Endereço para correspondência: Rua Barreto Leme, 991/31, Centro. Campinas, SP. CEP: 13010-201. Telefone: (19) 2121-8322. E-mail: aidapsico@yahoo.com.br.

3 AAIDD, atual denominação para AAMR (American Association on Mental Retardation), passou a usar o termo "deficiência intelectual" ao invés de "deficiência mental", de acordo com o site www.aaidd.org, retirado em 16.10.09. No presente trabalho foi adotada a denominação deficiência intelectual. importante ter em mente a coexistência das limitações e das potencialidades do avaliado. Assim, segundo Luckasson e cols., a descrição das limitações ajudará a desenvolver um perfil para os apoios necessários. Os autores acrescentam que apoios personalizados, apropriados e desenvolvidos por determinado período de tempo, ajudam a melhorar o funcionamento cotidiano dessas pessoas.

Essa definição leva em conta habilidades conceituais, sociais e práticas a serem consideradas em relação ao contexto social e cultural, e dá ênfase ao desenvolvimento das potencialidades das pessoas assim avaliadas. Em consonância com esse enfoque, diferentes autores (e.g., Denari, 1997; França Ribeiro, 2001) vêm apresentando a pessoa com deficiência intelectual como sujeitos de direitos, dentre os quais se inclui o exercício da sexualidade. Para tanto, vem sendo discutida a melhor forma de prepará-los para esse exercício. No que se refere à orientação sexual inserida no processo educacional regular, essa é uma questão relativamente nova para todos os alunos, e não apenas para os considerados com deficiência intelectual.

No Brasil, a orientação sexual nas escolas é normatizada pelos Parâmetros Curriculares Nacionais - PCN (Brasil, 1997). Essa orientação é encarada como uma ação complementar à educação sexual oferecida pelas famílias. Segundo o documento, a escola só deve se posicionar em relação aos 
valores familiares quando estes violarem os direitos das crianças e dos adolescentes estabelecidos no Estatuto da Criança e do Adolescente (ECA). No mais, é papel da escola fornecer informações corretas sobre os conceitos próprios da sexualidade humana, incentivar a pesquisa a respeito de como as diferentes culturas se relacionam com a sexualidade e explicitar e problematizar mitos e falsas crenças. Dessa forma, os PCN abordam a sexualidade em relação aos aspectos biológicos, psíquicos, sociais e culturais.

Quanto às pessoas com deficiência intelectual, levanta-se a questão sobre a forma como a sociedade caracteriza a sexualidade dessa população. Segundo Giami (2004), os pais e os profissionais que atendem as pessoas deficientes intelectuais representam sua sexualidade ora como inexistente, ora como exacerbada, encarando-as, respectivamente, como anjos ou feras. Para esse autor, os pais tendem a ver seus filhos como eternas crianças, portanto, sem a possibilidade do desejo sexual e com uma afetividade manifesta igual ou superior à de pessoas com desenvolvimento típico. De acordo com França Ribeiro (1995, 2001), a negação da sexualidade da pessoa deficiente intelectual pelos pais é uma forma de auto proteção não eficaz, mas compreensível. Concordando com o autor, é importante lembrar que os pais, ao aceitarem a sexualidade do filho, precisariam encarar as consequências do exercício da sexualidade, incluindo o direito à masturbação, a existência de sofrimento em uma relação amorosa, a possibilidade de uma gravidez, a procura de um método contraceptivo adequado, a preocupação com as DST, o acesso ao casamento etc.

Para vários autores (Denari, 1997; França Ribeiro, 2001; Glat, 1992), a maioria das pessoas com deficiência intelectual passa pelas mudanças da puberdade, que não acontecem apenas nos casos em que há severas alterações biológicas e fisiológicas. Os autores enfatizam que, em relação aos impulsos e desejos sexuais, essas pessoas manifestam necessidades, experiências e emoções semelhantes às dos demais adolescentes. O que se observa, em muitas ocasiões, é a inadequação da manifestação dos comportamentos sexuais, em decorrência da pouca convivência em grupos em que regras de conduta sejam cobradas.

No que se refere às reações de professores quanto às manifestações de sexualidade de seus alunos com deficiência intelectual, Maia (2001) e Maia e Aranha (2003) concluíram que os profissionais se sentiam despreparados para atuar diante das ocorrências de beijos e abraços entre seus alunos, ou da ocorrência de masturbação em público. Nesse contexto, a pessoa com deficiência intelectual é encarada como deficiente em relação à sexualidade e aos afetos (Maia, 2001). Ela é vista como uma pessoa incapaz de manter um vínculo afetivo, sendo apenas capaz de amor fraternal (Denari, 2002). Torna-se, assim, evidente que a relação entre sexualidade e deficiência intelectual é permeada por preconceitos e mitos que dificultam um trabalho sistematizado de orientação sexual. Por outro lado, vários esforços vêm sendo envidados no sentido de se reverter essa situação.

Foi realizada, em uma instituição filantrópica da Áustria onde seria viabilizado um projeto de orientação sexual, uma pesquisa com usuários e profissionais (Plaute, Westling \& Cizek, 2002), para levantamento das atitudes e conhecimentos que essas pessoas apresentavam sobre a sexualidade da pessoa com deficiência intelectual. Os autores verificaram que $70 \%$ dos usuários entrevistados não conversavam sobre sexualidade com seus pais ou com os profissionais que os atendiam e não compreendiam o termo "educação sexual", sendo concluído que esses usuários apresentavam poucos conhecimentos sobre sexualidade. Relataram, também, que os usuários demonstraram interesse em conversar sobre suas ansiedades e necessidades sexuais, sendo a entrevista, para muitos deles, a primeira oportunidade de falar sobre sua sexualidade. Em relação aos profissionais da instituição, os autores concluíram que eles tinham consciência da falta de informação dos usuários e que aprovavam a educação sexual para essa população. Entretanto, os dados indicavam que os profissionais não sabiam como lidar com as necessidades sexuais dessa população e temiam a reação dos pais, dos supervisores e da sociedade em geral. Esses dados corroboram as conclusões da pesquisa de Giami (2004), realizada na França na década de 1980, a respeito das representações dos profissionais em relação à sexualidade da pessoa com deficiência intelectual.

A partir dos resultados de sua pesquisa, Plaute e cols. (2002) propuseram na Áustria um modelo de educação sexual, do qual todos os indivíduos com deficiência intelectual acima de 17 anos de idade poderiam participar, independentemente do grau de sua capacidade. Foi verificado que os participantes gostavam dos encontros, que conversavam sobre os assuntos veiculados no programa em sua residência e no local de trabalho, e que o grau de informação aumentou após a participação no programa.

Entre 1998 e 1999, Gust, Wang, Grot, Ransom e Levine (2003) realizaram uma pesquisa nos Estados Unidos, a respeito do comportamento sexual de pessoas com deficiência intelectual acima de 18 anos de idade e residentes em instituições. Pesquisaram, entre outros aspectos, a realização de orientação sexual, frequência de relações sexuais consentidas e uso de camisinha. Os resultados indicaram que a maioria das instituições pesquisadas (88\%) realizava educação sexual, um dado divergente em relação aos de estudos realizados em outros locais. Outro resultado indicou que $45 \%$ das instituições permitiam a ocorrência de relações heterossexuais entre seus residentes, evidenciando, segundo os autores, a aceitação da sexualidade dos residentes. Dados diferentes foram relatados por Giami (2004), relativos a pesquisas realizadas em instituições francesas, nos anos 80. Esse autor constatou que as relações heterossexuais entre os internos não eram permitidas, mas que, de fato, ocorriam e com o conhecimento dos profissionais.

Ainda com relação ao estudo de Gust e cols. (2003), os autores constataram que dois terços da população estudada não usavam camisinha, disponível nas clínicas das instituições, e apontaram para a séria questão da transmissão das DST, principalmente do HIV. Na discussão dos resultados, os autores assinalaram a necessidade de se realizar educação sexual para todas as pessoas com diagnóstico de deficiência intelectual, inclusive para aquelas com dificuldades de comunicação.

No Brasil, um trabalho de orientação sexual foi relatado por Araújo (2002), envolvendo um grupo de adolescentes e jovens com diagnóstico de deficiência intelectual, em uma instituição de educação especial na cidade de UberlândiaMG. A autora concluiu que os alunos apresentavam interesse, mas pouca informação sobre sexualidade, a maior parte con- 
seguida com amigos e por meio da televisão, o que denotava o pouco acesso dessa população à informação correta. Outro dado relevante indicou que os alunos sabiam da necessidade de se usar camisinha, mas não sabiam como usá-la e também não compreendiam o porquê dessa necessidade.

Denari (1997), ao procurar compreender como o adolescente minimamente alfabetizado e com deficiência intelectual percebe sua sexualidade, e como se configura essa manifestação para a sua família e para a instituição que ele frequenta, realizou uma pesquisa em uma escola de educação especial localizada no interior do Estado de São Paulo. Para a coleta de dados, foram realizados encontros informais com os adolescentes para a discussão de temas relativos à sexualidade escolhidos por eles, pelo período de um ano. Foram, também, realizadas reuniões semanais com os pais e conversas com profissionais, nos intervalos das aulas. A autora constatou e criticou as tentativas da instituição de suprimir a sexualidade, buscando sublimá-la por meio de práticas esportivas e artísticas, ou reprimi-la pela vigilância constante aos alunos. Mostrou que os adolescentes demonstravam interesse em relação aos temas de sexualidade e que muitos apresentavam expectativas de namoro, casamento e filhos. Constatou, também, o pouco conhecimento sobre comportamentos sexuais, concepção, contracepção e DST entre os adolescentes, e a presença de atitudes preconceituosas em relação à homossexualidade.

Em relação à percepção dos pais a respeito das manifestações da sexualidade de seus filhos, Denari (1997) chegou à conclusão semelhante à dos estudos anteriormente relatados, a saber, negação da sexualidade dos filhos adolescentes, tratando-os como crianças. Quanto aos profissionais da instituição, a autora identificou certo desconforto na aceitação da sexualidade desses adolescentes e, como decorrência, uma vigilância acirrada para coibir possíveis manifestações de namoro.

Esses estudos ajudam a caracterizar as concepções relativas à sexualidade do jovem com deficiência intelectual, e apontam para a importância dos programas de orientação sexual para essa população, como reconhecimento de seus direitos de cidadãos.

Quando se fala em programas dessa natureza, a primeira idéia é a de que os jovens com deficiência intelectual teriam dificuldade na apreensão dos conteúdos apresentados. Carvalho (2006) também discute essa suposta incapacidade do jovem com diagnóstico de deficiência intelectual de se apropriar de conceitos e normas culturalmente construídas. A autora relata experiências de ensino, realizadas com jovens matriculados em escola de educação especial, em que muitas possibilidades foram oferecidas, e os jovens responderam com interesse, colaboração, e compreensão em diferentes níveis, para diferentes atividades.

$\mathrm{Na}$ orientação sexual para jovens com diagnóstico de deficiência intelectual, como em qualquer situação de ensino, buscam-se estratégias efetivas e, dentre essas, destaca-se o uso de recursos pedagógicos (modelos tridimensionais, gravuras, dramatizações etc.) que favoreçam a compreensão dos conceitos veiculados. É também importante buscar o estabelecimento de relações e vínculos entre as experiências pessoais dos educandos e as noções apresentadas nas aulas.
A questão do aproveitamento das experiências pessoais encontra fundamento, entre outros, na distinção feita por Vygotsky (1934/2000) em relação a conceitos cotidianos e científicos. De acordo com Mahn e John-Steiner (1998), Vygotsky via os conceitos cotidianos e científicos como aspectos do processo unificado de formação de conceitos, pois não os considerava como opostos. Segundo a discussão sobre as contribuições de Vygotsky, trazida por Van der Veer (1998), conceitos cotidianos estão relacionados ao que as crianças aprendem no dia-a-dia, por meio das interações com os adultos e com o seu ambiente. Esses conceitos não são apresentados de forma lógica e sistemática, e não formam, na mente da criança, um todo coerente e hierarquicamente ordenado. Já os conceitos científicos são introduzidos na escola, de forma sistematizada, com uma lógica própria, por meio de uma apresentação verbal explícita, como conhecimento consciente e deliberado.

Ainda segundo Van der Veer (1998), Vygotsky estava consciente da força e da fraqueza tanto dos conceitos cotidianos quanto dos conceitos científicos. A força dos conceitos cotidianos reside no fato de estes serem ricos em conotações provenientes da experiência direta, o que os torna menos vulneráveis ao esquecimento. Entretanto, os conceitos cotidianos podem estar baseados apenas em condições de validade local e as pessoas podem se referir a eles somente a partir de alguma contextualização, dependente de detalhes práticos, o que é indicativo de sua fraqueza. Já a força dos conceitos científicos está no fato de eles estarem embutidos e conectados a uma totalidade e de constituírem uma estrutura conceitual que, supostamente, reflete a verdadeira natureza da matéria sobre a qual se fala. Contudo, os conceitos científicos podem permanecer como uma fórmula verbal vazia, de aplicação limitada, facilmente esquecida, se não for enriquecida com experiências pessoais. Idealmente, $\mathrm{o}$ conhecimento conceitual genuíno deveria se basear nas forças combinadas dos conceitos cotidianos e científicos. Dessa forma, Van der Veer destaca a interdependência complexa e a influência bidirecional entre os conceitos científicos e cotidianos. Assim, os conceitos científicos sempre pressupõem os conceitos cotidianos em sua fundação e são capazes de transformá-los neste processo.

Alguns exemplos de estudos sobre formação de conceitos em ambientes educacionais, sob essa perspectiva, são apresentados a seguir. Um estudo sobre "cultura" em uma classe de $3^{\mathrm{a}}$ série do Ensino Fundamental de uma escola municipal da cidade de Campinas é relatado, em dois momentos, por Fontana $(1993,2000)$. As aulas eram programadas pela pesquisadora e pela professora e ministradas pela última. As estratégias de intervenção incluíram a apresentação de um desenho de uma aldeia indígena em atividade e perguntas realizadas pela professora sobre o que era observado no desenho. A partir das falas das crianças, a professora reorientou suas perguntas, introduzindo o termo "cultura". A autora analisou o processo de formação do conceito de "cultura", iniciado nas discussões sobre o tema entre alunos e professora. Ela analisou as falas dos alunos e destacou momentos em que eles utilizaram conceitos cotidianos para se referirem às ações supostamente representadas no desenho, tais como: abanar café e lavar roupa. Outros momentos foram considerados como indícios do processo de apreensão 
do conceito científico, quando, por exemplo, as crianças relacionaram cultura ao trabalho: homem pescando e mulher pintando outra mulher. A autora também analisou a mediação realizada pela professora por meio de suas perguntas e falas e considerou que o desenvolvimento das crianças e, sobretudo, as relações e interlocuções que se estabeleceram em sala de aula influenciaram as escolhas das estratégias de apreensão de conceitos pelas crianças.

Outro estudo é apresentado por Moura (1999). A autora investigou a organização conceitual dos trabalhadores que frequentavam uma classe de alfabetização do programa de educação para adultos da Faculdade de Educação da Universidade de São Paulo (USP). A pesquisadora atuou também como professora da sala, sendo o conceito de "ser vivo" selecionado para o estudo. A autora observou que os alunos apresentaram, inicialmente, conceitos sobre "ser vivo" com base em suas vivências, de forma contextualizada, como, por exemplo, a referência ao Rio São Francisco e ao trabalho com a terra na agricultura, que fazem parte das experiências do migrante nordestino, perfil característico da classe de alunos pesquisada. Ao longo das discussões em grupo, mediadas pela pesquisadora, e com a exigência constante de reflexão por parte dos participantes, a autora verificou que surgiram novos significados mais elaborados. Exemplo dessa elaboração é a afirmação de alguns alunos sobre a capacidade de a terra e de a água possibilitarem a vida, mas não possuírem vida como os seres vivos, diante de algumas falas de outros alunos associando terra e água aos seres vivos. A partir da interação entre os alunos e com a professora, novos significados foram construídos, reformulando o conceito de "vida" a cada nova demanda à qual o grupo procurava responder.

À semelhança desses estudos sobre formação de conceitos, é interessante compreender o processo de apreensão de conceitos sobre sexualidade dos adolescentes e jovens com diagnóstico de deficiência intelectual. $O$ enfoque recai na questão de como os novos conceitos se ligam às experiências prévias dos adolescentes e dos jovens e como estes os transformam, significando-os. Nesse sentido, os objetivos dessa pesquisa são: (a) apontar indícios sobre o processo de apropriação de conhecimentos e valores sobre sexualidade por esses adolescentes e jovens, nas aulas de orientação sexual, e (b) indicar aspectos do contexto que parecem favorecer ou dificultar essas apropriações.

\section{Método}

Trata-se de pesquisa qualitativa, explicitada por González Rey (2000/2002) como o estudo de inter-relações complexas e dinâmicas, abordadas de forma integral e não fragmentada, que permite compreender processos não diretamente acessíveis à experiência.

\section{Participantes}

Foi estudado um grupo de adolescentes e jovens matriculados no Ensino Fundamental (modalidade jovens e adultos) de uma instituição de educação especial localizada no interior do Estado de São Paulo. A turma era formada por 11 alunos, sendo focalizados, no presente estudo, os nove alunos que participaram de mais de duas aulas (dentre as cinco analisadas) e cujos pais assinaram o Termo de Consentimento Livre e Esclarecido. O projeto do presente trabalho foi aprovado pelo Comitê de Ética em Pesquisa da Faculdade de Ciências Médicas da Unicamp.

Os nomes apresentados para os participantes são fictícios, e a idade e hipótese diagnóstica estão de acordo com o prontuário da instituição: Beatriz, 17 anos, com deficiência intelectual (DI) moderada e paralisia cerebral (PC) tetraparética; César, 20 anos, com DI moderada; Elza, 17 anos, com DI leve, PC tetraparética e cardiopatia congênita; Hélio, 17 anos, com DI moderada e hidrocefalia com derivação ventrículo peritonial; Jane, 19 anos, com DI moderada; Nelson, 26 anos, com DI moderada e PC (hemiparético); Rogério, 20 anos, com DI moderada; Luiz, 17 anos, com DI moderada; e Wagner, 27 anos, com Síndrome de Down.

A maioria dos participantes da pesquisa ingressou na instituição na década de 90, período em que o processo de inclusão escolar no Brasil era bastante incipiente. Todos os sujeitos frequentavam a instituição por, no mínimo, cinco anos, sendo que três deles, desde o período pré-escolar. Os participantes não eram alfabetizados e alguns desenhavam o próprio nome. A maioria era independente em relação à higiene pessoal, à alimentação e à locomoção. Faziam exceção duas adolescentes cadeirantes (Elza e Beatriz), independentes apenas em relação à alimentação. Quanto ao nível socioeconômico, a maioria pertencia aos estratos menos favorecidos da população.

\section{Procedimento}

Foi escolhida para foco do estudo uma sala de aula cuja professora concordou com as videogravações, sendo todas as aulas de orientação sexual videogravadas pelo período de dois anos. Para essas aulas, foram utilizados recursos didáticos como modelo tridimensional do tronco (corpo humano), conjunto de bonecos com genitais ("Família Colchetes"), gravuras e fotos variadas, quadro imantado e camisinha masculina. As aulas eram, em princípio, semanais, mas deixavam de ocorrer em diferentes circunstâncias, tais como festas, feriados, reuniões etc.

Foram selecionadas para o presente estudo cinco aulas, transcritas e analisadas. Essas aulas foram escolhidas por serem representativas da temática da sexualidade e/ou por demanda específica da instituição, a saber: Corpo Humano - 33 min; Beijo - 31 min; Namoro - 32 min; Coito - 28 min; Camisinha/DST - 36 min. Além das videogravações, a pesquisadora manteve um diário de campo com o resumo da dinâmica da atividade e da participação dos alunos em cada aula e com acontecimentos relevantes durante o período da coleta de dados.

\section{Análise de dados}

As transcrições foram examinadas várias vezes e, a partir dessa leitura e das perguntas que permeiam este trabalho, foram definidas categorias, que nortearam a análise, a saber: 
(a) Compreensão do tema: perguntas e/ou comentários sobre as falas da professora e de outros participantes, relacionados ao tema de forma pertinente.

(b) Pouca compreensão sobre o tema: repetições das falas do interlocutor, respostas parcialmente corretas e pouco elaboradas, aceitação da orientação da professora ou da pesquisadora nas atividades práticas, comentários sobre material didático, sem explicitação de compreensão do tema da aula.

(c) Nenhuma compreensão do tema: respostas erradas, execução de tarefas práticas de forma errada, declarações de que não sabe a resposta, silêncio diante de perguntas da professora ou da pesquisadora.

(d) Embaraço em relação ao tema: indicativos de inibição ou ansiedade (risos "nervosos", piadas, silêncio, cabeça baixa etc.) relacionados ao tema.

As aulas transcritas foram organizadas em episódios, sendo esses definidos como uma sequência de diálogos e atividades com unidade temática (definição adaptada a partir de Pedrosa \& Carvalho, 2005). Foram selecionados, e serão apresentados, oito episódios, extraídos das diferentes aulas anteriormente mencionadas, que exemplificam: (a) apropriação e compreensão dos conceitos, (b) dificuldades parciais de compreensão e (c) embaraço e inibição em relação ao tema sexualidade.

\section{Resultados e Discussão}

\section{Apropriação e compreensão dos conceitos}

Episódio 1-Colocando a camisinha (aula "Camisinha) DST'). Após demonstrar como se coloca a camisinha, utilizando uma camisinha masculina e uma cenoura, a pesquisadora pergunta aos alunos quem gostaria de repetir a atividade. O aluno Hélio se apresenta para a demonstração. A professora indaga se a pesquisadora quer que filme a atividade ("Quer que eu filme ele fazendo isto?"), aparentemente inibida pela estratégia de demonstração. Em seguida, a pesquisadora auxilia os alunos a identificarem o prazo de validade da camisinha, entrega a embalagem ao aluno Hélio e pergunta como ela deve ser aberta.

Hélio: (tenta abrir) Eta!

Diante da dificuldade apresentada pelo aluno, a pesquisadora explica que a embalagem possui um local por onde deve ser aberta.

Hélio: (pega e abre a embalagem)

A pesquisadora pede ao aluno para tirar a camisinha da embalagem e ele faz como orientado. Em seguida, ela solicita que ele assopre para verificar o lado que a camisinha desenrola.

Hélio: (puxa a parte inicial da camisinha com as duas mãos, assopra, segura a parte inicial da camisinha com a mão esquerda e puxa o corpo da mesma com a mão direita, desenrolando um pouco o corpo da camisinha).

A pesquisadora explica que ele deve torcer a ponta da camisinha onde fica o sêmen, quando da ejaculação, para que não fique ar nesse espaço, evitando que a camisinha es- toure. Em seguida, segura a cenoura para que Hélio coloque a camisinha.

Hélio: (segurando a ponta da camisinha com a mão esquerda, coloca a camisinha na cenoura e com a mão direita puxa o corpo da camisinha cobrindo a cenoura).

Hélio demonstra compreensão da tarefa, realizando-a sob orientação e com autonomia crescente ao longo do episódio. Anotações do diário de campo indicam que Hélio possuía uma camisinha em sua carteira, mas não sabia como manuseá-la, o que justifica o nível de detalhamento utilizado na demonstração. Esse desconhecimento de Hélio sobre questões sexuais é semelhante ao descrito na maioria das pesquisas mencionadas anteriormente. $\mathrm{O}$ jovem com deficiência intelectual, além de não receber, normalmente, orientação sexual da família ou da escola (com exceção dos programas recentes), tende a ser mais isolado, mais tutelado, sendo reduzidas as oportunidades de aprender com parceiros.

Episódio 2 - Camisinha evita DST (aula "Camisinha) $\left.\boldsymbol{D S} \boldsymbol{T}^{\prime \prime}\right)$. Ao final da explicação sobre DST, a pesquisadora mostra fotos nas quais aparecem genitais infectados por condiloma, explica os sintomas, enfatiza a necessidade do uso de camisinha como prevenção às DST e comenta: "Você nunca sabe se a pessoa com quem você vai transar tem ou não uma doença dessas".

Hélio: E a pessoa não fala também.

Nesse episódio, Hélio faz um acréscimo à fala da pesquisadora, demonstrando que entendeu a explicação. Durante a aula, Hélio manteve atenção às explicações do tema, tendo sido um dos participantes que mostrou maior nível de compreensão quanto às explicações dadas.

\section{Dificuldades parciais de compreensão}

Vários episódios foram selecionados de uma atividade realizada na aula "Namoro". A pesquisadora sugeriu a realização de um teatro com bonecos manuseados pelos alunos, tendo sido encenado o encontro entre dois adolescentes, Tiago (Nelson) e Mônica (Jane). O enredo foi criado pelo grupo, ao longo da encenação.

Episódio 3-Apresentação (aula "Namoro"). A história se iniciou no pátio da escola, no intervalo entre as aulas. A professora perguntou se Tiago ficou interessado quando viu Mônica.

Jane: (quando Mônica passa por Tiago, Jane joga a boneca em cima do boneco, e faz com que ela dê um beijo na boca dele) Hum!

Hélio: Ficou.

Elza: Ficou.

Jane: (ri)

A pesquisadora conduziu a história, perguntando se Tiago foi atrás da Mônica, e Hélio respondeu afirmativamente. Jane, novamente, tentou fazer a Mônica dar outro beijo na boca do Tiago, e os alunos reagiram à sua atitude.

Hélio: Para! (dirigindo-se a Jane).

Rogério: $O$, Jane!

Nelson: (puxa o boneco para o lado esquerdo da mesa, para desviá-lo da boneca).

Neste trecho, era esperado que Jane fizesse a boneca caminhar. Como ela não realizou o movimento, Rogério a 
ajudou. A professora comentou que Tiago tinha ido atrás da Mônica, e perguntou se ele queria conhecê-la.

Hélio: Quer. Vai trocar uma ideia.

Professora: $O$ que ele vai falar para ela?

Elza: Conversar.

Ainda no início da atividade, observou-se que Jane teve dificuldade para compreender e realizar a ação solicitada, a saber, manipular a boneca. Ao mesmo tempo, Jane estava interessada na atividade e dela participou com a ajuda dos colegas. A atitude de Jane, de jogar a boneca em cima do boneco, fazendo com que Mônica beijasse Tiago na boca, pode ser entendida como falta de recursos para demonstrar interesse pelo outro, de modo socialmente prescrito. Essa questão também é mencionada na literatura da área (França Ribeiro, 2001). De acordo com anotações no diário de campo, Jane tinha vida social restrita à escola e à casa de alguns parentes, e a aula de orientação sexual parecia ser uma das únicas fontes de informação sobre os comportamentos sociais esperados sobre conquista e namoro. Ainda de acordo com essas anotações, alguns meses antes, Jane tinha beijado na boca o colega que se sentava ao seu lado na aula. A coordenadora pedagógica imediatamente conversou com a aluna e, posteriormente, com a aluna e sua mãe, na presença da coordenadora da saúde. Houve reincidência, e a aluna foi suspensa por três dias. Na primeira vez em que a mãe foi chamada, ela informara que Jane também apresentava esses comportamentos em casa: quando um primo adolescente ia visitá-las, ela se sentava no seu colo e tentava beijá-lo na boca. $\mathrm{O}$ mesmo padrão repetiu-se na encenação, e Jane foi censurada de forma branda pelos colegas. Além disso, Hélio e Elza explicitaram alternativas socialmente aceitas para a "conquista". Dessa forma, observou-se que os colegas passaram a também mediar o processo de apropriação de valores e normas culturalmente prescritos para namoro.

Episódio 4-Lembrando as regras (aula "Namoro"). Os alunos encenam a despedida de Tiago e Mônica, após tocar o sinal para retorno à sala de aula. A pesquisadora perguntou como ia ser a despedida.

Elza: Beijo no rosto.

Hélio: $A h$ !

Pesquisadora: Na escola pode?

Elza: Não.

Jane: Não.

Diante da impossibilidade de se despedirem com um beijo, Hélio sugeriu que Tiago e Mônica saíssem das dependências da escola. Como isto também não era possível naquele momento, ele teve outra ideia:

Hélio: Pegar na mão.

Elza: Falar tchau.

A pesquisadora solicitou que Tiago e Mônica se despedissem, e ficou decidido que Elza falaria por Mônica. Eles se despediram com um tchau.

Em muitos episódios, a apropriação de práticas sociais não se deu por uma única experiência. No presente caso, parece que essa apreensão de Jane está relacionada às diferentes atitudes apresentadas pelos colegas e pela pesquisadora, dentre elas: censura do grupo diante de suas atitudes, sugestão da conversa como uma estratégia de aproximação indicada pelos colegas e a explicitação das regras da escola pela pesquisadora.
A escolha do teatro, como estratégia para a apropriação de práticas sociais, está de acordo com as propostas de França Ribeiro (2001). Para esse autor, é importante que pais e educadores ajudem as pessoas com deficiência intelectual a elaborar conceitos sobre sexualidade, usando situações e exemplos compatíveis com a compreensão dos mesmos, o que ficou evidenciado no presente exemplo.

Episódio 5-Beijo na boca (aula "Namoro"). Na sequência da encenação, Mônica e Tiago se encontram no sábado à noite para irem a uma sorveteria. Lá, Tiago pede Mônica em namoro, e eles se beijam na boca. Jane novamente joga Mônica em cima de Tiago. Quando retornam para a casa de Mônica, eles se despedem com um beijo na boca.

Jane: (toma a iniciativa, aproxima os bonecos, e faz o barulho do beijo com a boca).

Hélio pede licença, pega os bonecos e os prende com os colchetes da boca, simulando um beijo mais longo. Nesse caso, as duas modalidades de beijo foram aceitas pelo grupo, pelo fato de os personagens já serem namorados, contrastando com os episódios anteriores, quando se tratava das primeiras aproximações do casal.

As descrições dos episódios 3 a 5 mostram diferentes níveis de compreensão e de adoção das normas socialmente prescritas do namoro. As ações de Jane indicam uma variabilidade, evidenciando um processo não linear, com idas e vindas. A proposta de orientação sexual para esses alunos, portanto, está de acordo com a afirmação de Plaute e cols. (2002), de que o grau de deficiência não deve ser empecilho para a participação do jovem no grupo de orientação sexual. A atividade de encenação propiciou a expressão de diferentes formas de aproximação de práticas sociais referentes ao namoro e evidenciou modalidades de censura relativamente brandas. Dessa forma, foram trabalhados os aspectos emocionais e atitudinais envolvidos no desempenho da sexualidade, o que está de acordo com os autores acima citados. Vygotsky (1931/1997) também afirma que o aluno com deficiência intelectual necessita, mais do que o aluno com desenvolvimento típico, que a escola desenvolva nele o embrião do pensamento, pois, abandonado à sua própria sorte, não chega a desenvolvê-lo. O autor defende que é papel da escola propiciar ao aluno com deficiência intelectual uma concepção científica do mundo, para que ele possa descobrir as relações entre os fenômenos fundamentais da vida e formar uma atitude consciente perante o futuro.

\section{Embaraço e inibição}

Os episódios a seguir exemplificam embaraço e inibição e são considerados mistos, pois também foram categorizados em termos de grau de compreensão dos participantes.

Episódio 6-Quando transa, grita? (aula "Coito"). Ao final da aula, a pesquisadora pergunta sobre os motivos para uma relação sexual, na expectativa de que os alunos citem prazer, amor e reprodução, conforme havia sido explicado. Elza responde que as pessoas transam porque gostam, e os demais alunos permanecem em silêncio. A pesquisadora, então, passa a falar sobre outro motivo, a reprodução, e Elza pergunta:

Elza: Quando transa, grita? 
A pesquisadora volta a atenção para Elza, e ela repete a pergunta.

Rogério: (ri)

Hélio: (ri).

Elza: Isto que eu queria saber.

Para entender a possível origem da pergunta, a pesquisadora indaga se ela já ouviu alguém gritando ou se alguém lhe falou sobre isso.

Elza: Não. Já vi na televisão (ri).

Hélio: Ah, bom! (parece ficar mais confortável por não se tratar de experiência direta).

Pesquisadora: $O$ que vocês acham? (dirigindo-se aos alunos).

Todos: Silêncio.

A pesquisadora repete a pergunta. Elza responde afirmativamente e Hélio balança a cabeça em sinal de negativa. Em seguida, a pesquisadora explica sobre as possíveis reações de prazer em uma relação sexual.

Nesse episódio, observa-se que Elza participa ativamente fazendo perguntas e respondendo às questões apresentadas pela pesquisadora. Durante a aula, fica evidente que uma experiência cotidiana, novela na TV, é a base para a pergunta da aluna. A pesquisadora, então, aproveita para sistematizar o conhecimento, discorrendo sobre motivos para relação sexual, e formas habituais de expressão de prazer. Elza parece confortável na situação, ao contrário de Hélio e Rogério, que apresentam várias manifestações de embaraço. Apesar de participarem das aulas há algum tempo, era difícil, para eles, mostrar naturalidade com o tema, em geral pouco veiculado na interação com educadores (professores, pais, familiares) e, geralmente, restrito às conversas entre parceiros.

Episódio 7 - Reconhecendo parceiros homossexuais (aula "O Beijo"). A pesquisadora entrega um cartão para cada aluno contendo uma figura de revista no qual aparece um determinado tipo de beijo: no rosto, na boca, na testa etc., entre diferentes pessoas. A atividade, preparada por uma professora, acabou trazendo a questão da homossexualidade para discussão, por apresentar uma figura com parceiros homossexuais. Nessa figura, os homens estão de costas em primeiro plano e, ao fundo, aparece uma festa. O homem da esquerda está beijando o ombro do homem da direita e o está abraçando.

Ao iniciar a aula, a pesquisadora solicita que Beatriz mostre sua figura aos colegas. Ela está com a figura dos parceiros homossexuais.

Elza: O que é isto?

Hélio: Oxe! Calma aí! (pega a figura com a mão direita)

Nelson: (ri)

A pesquisadora pede que a figura seja passada para todos. Hélio pega a figura da Beatriz e a entrega para Elza. A pesquisadora solicita que os alunos descrevam a figura.

Hélio: (ri)

Beatriz: (ri)

Elza: (pega a figura e abaixa a cabeça para vê-la). Parece um homem.

Pesquisadora: Só um?

Hélio: São dois.

Elsa: (concorda).

Hélio: (passa a figura para César). Isso é ... sapatão!
Observa-se que os alunos demonstram embaraço ao descrever a figura. Essas dificuldades se evidenciam pelos risos de Nelson, Hélio e Beatriz, pela brincadeira do Hélio e pelas colocações de Elza. A fala sobre dois homens na figura é um indício de que os alunos reconhecem os parceiros homossexuais. Observa-se que Hélio reconhece tratar-se de parceiros homossexuais, quando o nomeia com um termo jocoso usado para descrever parceiras homossexuais. Os alunos parecem reproduzir o que usualmente se observa quanto ao tema: sabem que se trata de parceiros homossexuais, inclusive sobre suas conotações negativas, mas têm dificuldades para se expressarem verbalmente. Essa maneira de agir indica conhecimento sobre os modos como o tema é habitualmente tratado: silêncio, crítica velada ou explícita e zombarias.

Episódio 8 - "Apelidos" dos homossexuais. Ainda na mesma atividade, situação em que os alunos estão falando menos que o usual, a pesquisadora comenta sobre o abraço e o beijo entre os homens. Quando a pesquisadora pergunta para Beatriz o que é possível dizer a partir do que eles estão vendo na figura, Nelson comenta:

Nelson: É meio estranho, Aida.

Pesquisadora: É meio estranho? Vocês estão estranhando?

Hélio: Tô, sim!

Wagner: (segura a figura com a mão direita e olha para ela) É estranho!

Elza reafirma tratar-se de dois homens. A pesquisadora, então, pergunta se não podem ser parceiros homossexuais.

Hélio: Eu falei. É o que então?

Pesquisadora: Homossexual.

Hélio: Não. Tem apelido também (termo usado pela pesquisadora para se referir aos termos jocosos e preconceituosos para nomear questões da sexualidade).

A pesquisadora pergunta qual é o apelido, Beatriz sorri e Hélio, rindo, diz que não sabe. Nelson comenta que os dois homens estão encostados um no outro e a Elza pergunta:

Elza: É gay?

Hélio: (ri)

Pesquisadora: Mas tem outros apelidos. Bicha, veado. Não é assim que as pessoas falam?

Nelson: $\dot{E}$.

Observam-se fortes sinais de embaraço para a questão da homossexualidade: os alunos não descrevem a figura, mesmo após Hélio falar em "sapatão", ao final do episódio anterior; Beatriz e Hélio continuam a rir durante os diálogos sobre o tema; Nelson, Hélio e Wagner parecem estranhar o que veem. Nesse segundo episódio, Hélio pergunta sobre os termos populares para a homossexualidade masculina, Elza utiliza um termo da língua inglesa bastante usual e Nelson parece reconhecer os termos jocosos explicitados pela pesquisadora.

Alguns estudos abordaram a visão da pessoa com deficiência intelectual sobre a homossexualidade (Aunos \& Feldman, 2002; Denari, 1997). De acordo com Aunos e Feldman, poucas pessoas com deficiência intelectual, apenas $33 \%$ da amostra, disseram aceitar a homossexualidade. Já Denari concluiu que as falas dos adolescentes participantes de sua pesquisa, muitas vezes, associavam homossexualidade a patologias e disfunções. Esses dados podem ser interpretados como reflexo de uma visão conservadora em relação 
à homossexualidade, indicando a apreensão dos valores e modos de agir da sociedade.

\section{Considerações Finais}

À semelhança do que se observa com os alunos que freqüentam o ensino regular, os alunos não formavam um grupo homogêneo em relação à apropriação de conceitos sobre sexualidade. Assim, diferentes alunos apresentaram diferentes níveis de compreensão, como se depreende da análise dos episódios 1 a 5 . Dentre os possíveis aspectos que podem ter contribuído para essa compreensão, salienta-se o resgate de experiências pessoais (conceitos cotidianos) e o estabelecimento de relações entre estas e os conhecimentos formais veiculados (conceitos científicos). Exemplo disso foram as explicações técnicas sobre o modo de colocar a camisinha, assim como sobre a função da mesma, relacionando essas explicações às experiências anteriores dos alunos, que eram incompletas e parciais. Também o uso de recursos pedagógicos e as propostas de atividades diversificadas, como o teatro e a demonstração da colocação da camisinha, favoreceram essa apreensão.

Outro aspecto a ser comentado refere-se à observação de que os alunos, por várias vezes, manifestavam valores e preconceitos semelhantes aos de seus grupos sociais, especialmente no que se referia à homossexualidade e aos padrões aceitáveis de contato físico nas diferentes etapas da conquista e do namoro. Também se constatou que eles entendiam e seguiam as regras estabelecidas para o funcionamento do grupo, discutidas a cada início de período letivo. As regras para as aulas de orientação sexual incluíam, entre outras, o respeito ao colega, à professora e à pesquisadora, e à proibição de se masturbar em público. Essas regras foram apreendidas, sendo raramente quebradas (e, quando isso ocorria, havia censura dos demais colegas). Observou-se, portanto, uma constante apropriação de valores e normas culturalmente estabelecidos, o que pode ser considerado, também, um indicador de capacidades desses jovens.

No caso do presente estudo, os sinais mais acentuados de embaraço foram observados, para a maioria dos alunos, nas aulas sobre "Coito" e na aula "Beijo", quando surgiu o tema homossexualidade, provavelmente, por serem temastabus para a sociedade em que vivem. Já as explicações sobre camisinha e DST, apesar de evocarem certo embaraço, trouxeram um grande interesse e curiosidade, levando a uma participação intensa na atividade. Propagandas incentivando o uso da camisinha são constantemente veiculadas na mídia, o que pode ter contribuído para o interesse pelo tema, que se sobrepôs, nas aulas, às manifestações de embaraço.

Ainda em relação às aulas de orientação sexual, consta das anotações do diário de campo o relato de uma monitora da instituição, sobre a diminuição de incidência de tentativas do ato sexual nos banheiros da instituição, depois que essas aulas passaram a ser oferecidas. É provável que isso tenha se devido, em parte, à possibilidade de explicitar dúvidas e falar sobre o tema, bem como à possibilidade de receber explicações sistematizadas sobre sexualidade. Observação nesse sentido é apresentada nos Parâmetros Curriculares Nacionais - PCN (Brasil, 1997), em que se afirma que as escolas que realizam orientação sexual para seus alunos constatam a diminuição da tensão e preocupação com questões da sexualidade, e o aumento da solidariedade e respeito entre os alunos.

Além disso, os diferentes níveis de compreensão sobre sexualidade de pessoas com deficiência intelectual apresentadas por este estudo contrastam com a visão mítica que os caracteriza por suas incapacidades. Os resultados sugerem novos estudos voltados para a análise das competências de jovens com deficiência intelectual em relação à sexualidade e sua contribuição para transformação dessas pessoas em sujeitos de direitos.

\section{Referências}

Araújo, A. (2002). Educação sexual com adolescentes e jovens portadores de deficiências mentais. Revista da Sociedade de Psicologia do Triângulo Mineiro, 6, , 63-69.

Aunos, M., \& Feldman, M. A. (2002). Attitudes towards sexuality, sterilization and parenting rights of persons with intellectual disabilities. Journal of Applied Research in Intellectual Disabilities, 15, 285-296.

Brasil. (1997). Parâmetros curriculares nacionais: pluralidade cultural, orientação sexual. Brasília: MEC/Secretaria de Educação Fundamental (SEF).

Carvalho, M. de F. (2006). Conhecimento e vida na escola: convivendo com as diferenças. Campinas: Unijuí.

Denari, F. E. (1997). O adolescente especial e a sexualidade: nem anjo, nem fera. Tese de Doutorado, Universidade Federal de São Carlos, São Carlos.

Denari, F. E. (2002). Sexualidade \& deficiência mental: reflexões sobre conceitos. Revista Brasileira de Educação Especial, 8, 9-14.

Fontana, R. A. C. (1993). A elaboração conceitual: a dinâmica das interlocuções na sala de aula. Em A. L. Smolka \& M. C. R. de Góes (Orgs.), A linguagem e o outro no espaço escolar: Vygotsky e a construção do conhecimento (pp. 119-149). Campinas: Papirus.

Fontana, R. A. C. (2000). Mediação pedagógica na sala de aula (3 $3^{\text {a }}$ ed.). Campinas: Autores Associados.

França Ribeiro, H. C. de (1995). Orientação sexual e deficiência mental: estudos acerca da implementação de uma programação. Tese de Doutorado, Universidade de São Paulo, São Paulo.

França Ribeiro, H. C. de (2001). Sexualidade e os portadores de deficiência mental. Revista Brasileira de Educação Especial, 7, 11-27.

Giami, A. (2004). O anjo e a fera: sexualidade, deficiência mental, instituição (L. Macedo, Trad.). São Paulo: Casa do Psicólogo.

Glat, R. (1992). A sexualidade da pessoa com deficiência mental. Revista Brasileira de Educação Especial, 1, 65-74.

González Rey, F. L. (2002). Pesquisa qualitativa em Psicologia: caminhos e desafios (M. A. F. Silva, Trad.). São Paulo: Pioneira Thomson Learning (Trabalho original publicado em 2000).

Gust, D. A., Wang, S. A., Grot, J., Ransom, R., \& Levine, W. C. (2003). National survey of sexual behavior and sexual behavior policies in facilities for individuals with mental retardation/developmental disabilities. Mental Retardation, 41, 365-373. 
Luckasson, R., Borthwick-Duffy, S., Buntinx, W. H. E., Coulter, D. L., Graig, E. M., Reeve, A., Schalock, R. L., Snell, M. E., Spitalnik, D. M., Spreat, S., \& Tassé, M. J. (2006). Retardo Mental: definição, classificação e sistemas de apoio. (10ª . ed.) (M. F. Lopes, Trad.). Porto Alegre: Artmed.

Mahn, H., \& John-Steiner, V. (1998). Introduction. Mind, Culture, and Activity, 5, 81-88.

Maia, A. C. B. (2001). Reflexões sobre a educação sexual da pessoa com deficiência. Revista Brasileira de Educação Especial, 7, 35-46.

Maia, A. C. B., \& Aranha, M. S. F. (2003). Análise do relato de uma professora de educação especial sobre a sexualidade de seus alunos com deficiência mental. Em M. C. Marquezine, M. A. Almeida \& E. D. O. Tanaka (Orgs.), Educação Especial: políticas públicas e concepções sobre deficiência (pp. 67-78). Londrina: Eduel.

Moura, M. P. (1999). A organização conceitual em adultos pouco escolarizados. Em, M. B Oliveira \& M. K. Oliveira (Orgs,), Investigações cognitivas: conceito, linguagem e cultura (pp. 101113). Porto Alegre: Artes Médicas Sul.

Plaute, W., Westling, D. L., \& Cizek, B. (2002). Sexuality education for adults with cognitive disabilities in Austria: Survey of attitudes and the development of a model program. Research \& Practice for Persons with Severe Disabilities, 27, 58-68.
Pedrosa, M. I., \& Carvalho, A. M. A. (2005). Análise qualitativa de episódios de interação: uma reflexão sobre procedimentos e forma de uso [versão eletrônica]. Psicologia: Reflexão e Crítica, $18,431-442$.

Van der Veer, R. (1998). From concept attainment to knowledge formation. Mind, Culture, and Activity, 5, 89-94.

Vygotsky, L. S. (1997). Obras escogidas, V-Fundamentos de defectología (J. G. Blank, Trad.; N. J. V. Vargas \& I. Filanova, Revisores). Madri: Visor. (Trabalho original publicado em 1931).

Vygotsky, L. S. (2000). A construção do pensamento e da linguagem. (P. Bezerra, Trad.). São Paulo: Martins Fontes. (Trabalho original publicado em 1934).
Recebido em 22.10.2007

Primeira decisão editorial em 05.08.2008

Versão final em 03.03.2010

Aceito em 19.04.2010 